\title{
Haití: el primer grito de libertad americano
}

Haiti: o primeiro grito americano de liberdade

Haiti: the first American bawl of freedom

María José Becerra

\section{Resumen}

En este trabajo intentaremos analizar los cambios que se produjeron en el proceso revolucionario haitiano, tratando de comprender su originalidad y complejidad. Sus particularidades -de lo que comenzó como una rebelión económico-social y que culminó con la lucha por la independencia-, tensiones y contradicciones, objetivadas en variables estructurales propias de la lógica colonial en Saint Domingue/Haití, se conjugan con ciertos aspectos coyunturales, definiendo el nacimiento e identidad de la primera Republica de ex-esclavos negros en el mundo.

Palabras clave: Haití. Revolución haitiana. Rebelión de esclavos.

\section{Introducción}

Nos han enseñado que el primer país de América en alcanzar su independencia fue Estados Unidos. Sin embargo, como bien dice Eduardo Galeano, esta independencia no fue para todos sus habitantes. Estados Unidos siguió teniendo, por muchos años más, una alta población de negros esclavizados. Entonces, no es el primer Estado totalmente independiente de América.

Este error no obedece a un descuido historiográfico, sino a un deliberado ocultamiento de la realidad: el primer Estado en alcanzar la independencia en América fue Haití.

Licenciada en Historia; Magíster en Relaciones Internacionales. Docente e investigadora de la Universidad Nacional de Córdoba (Argentina) y de la Universidad Nacional de Tres de Febrero (Argentina).

Recebido em 15/11/2012 Aprovado em 14/01/2013

http://dx.doi.org/10.5335/hdtv.13n.1.3049 
¿Por qué la Historia se olvidó de la independencia de Haití? ¿Por qué no se enseña en las clases de historia en las escuelas, o por qué ocupa un reducido espacio en las curriculas universitarias?

Además, nos encontramos con que existe escasa bibliografía sobre el proceso independentista haitiano. Sin embargo en los últimos años han aparecido una serie trabajos, como el de Eduardo Gruner ${ }^{1}$ o el de María Cecilia Feijoo y Fernando Scolnik, ${ }^{2}$ que nos muestran que la situación en Haití fue compleja, en donde la articulación de los procesos internos propios de esta colonia francesa se conjugaron con los cambios que se estaban desarrollando en la metrópoli y, según Gruner, en la conformación del sistema mundo. Por su parte no podemos dejar de mencionar el señero libro de Cyril Lionel James. ${ }^{3}$ En su obra -aunque escrita en la década del treinta del siglo $X X$, sigue siendo un trabajo fundamental para entender la historia haitiana-, el autor nos muestra a los esclavos como los agentes de su propia historia, quienes jugaron un papel preponderante en el desarrollo de la independencia. A través del estudio sobre Toussaint Louverture, uno de los líderes de la rebelión de esclavos, analiza cómo los trabajadores no libres de la colonia llevaron adelante una revolución radical que reinterpretó a su manera los postulados de la Revolución Francesa de libertad y universalidad. Esto se concretó a través de una trascendental articulación política entre ambos procesos revolucionarios, el de la metrópoli y el de la colonia. La asociación entre los delegados metropolitanos y los líderes de los esclavos rebeldes, expresó una alianza de clases entre los saint-culottes de las comunas de París y los esclavizados de Saint Domingue, posibilitando la liberación efectiva de las relaciones estamentales, feudales y de esclavitud, de cada lado. Esta radicalización llevó a James a denominar a los rebeldes como "jacobinos negros".

Del que sí se escribieron numerosos ensayos literarios o históricos fue de Toussaint Louverture, como un hombre americano implicado en las ideas de la Revolución Francesa. Pero, ¿por qué no se lo enseña en las escuelas, en las universidades, junto a los otros "padres de la patria" americana?

Aunque no hay una respuesta clara a estas preguntas podemos decir que quizás se deba a que fue la primera revolución de negros esclavos que tomó el poder en el mundo. La primera revolución de esclavos que terminó con el poder colonial y que además radicalizó los ideales de la Revolución Francesa, haciendo verdaderamente universales los derechos por ella pregonados. Es la primera donde se combinó una revolución económico-social que transformó toda la estructura de clase en la colonia, con una revolución política anticolonial. O quizás sea porque la revolución haitiana no se quedó encerrada en sus fronteras sino que, en las primeras décadas del siglo XIX, apoyó y ayudó a los independentistas americanos a liberarse del yugo colonial. ${ }^{4}$

Esta lucha anticolonial en Saint Domingue, se fue "construyendo", por así decir, al articularse elementos internos propios del sistema político, económico y socio-cultural de la isla con los sucesos que ocurrían en la propia metrópoli. Sin duda, la vinculación entre factores que podríamos denominar "tradicionales" con los "modernos" es la 
base de la particularidad de la independencia haitiana. Esta relación dialéctica fue lo que determinó lo que podríamos denominar como un sentido de identidad, de pertenencia, característica singular de esta revolución. Intentaremos así delinear cuáles fueron los elementos que posibilitaron que la revuelta de los esclavos que estalló en 1791, en el Norte de Haití, se transformara en una lucha de liberación colonial, para poder valorar su vinculación con los hechos que se estaban desenvolviendo en Francia. Asimismo destacaremos los factores que permitieron dar cohesión a este movimiento.

Para comprender el proceso revolucionario partiremos de una breve reseña histórica en donde destacaremos el desarrollo productivo en cada una de las áreas de la colonia francesa de Saint Domingue. Aquí veremos cómo se conformó la sociedad y cómo ésta se articuló con la metrópoli. En un segundo apartado describiremos los elementos característicos de esta sociedad colonial. Veremos cómo estos fueron plasmando una sociedad con ciertas y determinadas características que al articularse con los cambios que se estaban dando en el sistema internacional, hicieron eclosión y pusieron de manifiesto estas contradicciones. En el último apartado analizaremos las diferentes alianzas que se formaron para transformar una revuelta social en una lucha por la independencia.

\section{La historia colonial en Haití}

El 1 de enero de 1804, Jean Jacques Dessalines, general en jefe del primer país libre de América, proclamó la independen- cia de la que hasta ese momento había sido la colonia francesa de Saint Domingue. Sus libertadores decidieron que llevaría su nombre indígena: Haití, tierra de montañas. ${ }^{5}$

Este pequeño territorio insular ${ }^{6}$ pasó definitivamente a manos francesas en 1697 como parte de un tratado entre España quien la colonizó en primer lugar- y Francia. ${ }^{7}$ Sin embargo la presencia gala en la región del Caribe era notoria desde hacia tiempo, debido al interés que las riquezas americanas -en especial el oro y la plata, pero también los productos agrícolas de exportación como el azúcar, el tabaco, el cacao, etc.- despertaban en los Estados europeos. A lo que se le sumaba el férreo control que España ejercía sobre sus territorios coloniales, impidiéndoles el comercio directo con otros países. Todo esto motivó la piratería y el comercio ilegal. Francia no escapó a estas prácticas. Los piratas, bucaneros y filibusteros galos asolaron las colonias españolas, en particular las caribeñas.

La fuerte necesidad de mano de obra hizo que desde épocas muy tempranas los españoles introdujeran esclavos africanos a las islas del Caribe, en especial a La Española, ${ }^{8}$ para desarrollar las tareas productivas que hacían a la riqueza de la Corona. La dureza del sistema esclavista español y el trato que los amos daban a los esclavos, hizo que muchos huyeran a las montañas, formando así comunidades cimarronas importantes, con una cultura y una organización social distinta a la europea. Como consecuencia de esto, la mano de obra esclava comenzó a escasear. A esto se le sumó la perdida de interés en la isla por parte de la Corona ibérica -debido a la riqueza de México y del Perú-, 
lo que llevó a un fuerte despoblamiento, salvo la ciudad de Santo Domingo, ubicada en la parte oriental.

Por el contrario, la parte norte y la occidental fue creciendo en importancia, tanto a nivel demográfico como productivo, debido a la presencia francesa. Las primeras ocupaciones fueron informales. Las hicieron bucaneros, filibusteros y piratas ingleses y franceses, $\mathrm{y}$, posteriormente, se asentaron los colonos franceses atraídos por las perspectivas económicas que poseía La Española. .

Ya desde principios del siglo XVII, se había desarrollado en la isla el cultivo de la caña de azúcar, introducida por los españoles desde Canarias. Para 1618 se instaló el primer ingenio azucarero, y a partir de entonces comenzó su producción industrial para la exportación.

Cuando se instalaron los franceses en la parte norte y occidental de la isla, continuaron con la producción de azúcar. Esta era la gran riqueza de la isla, formándose una "sacarocracia" sumamente influyente en lo económico. Y, aunque Francia ejercía un sistema monopólico comercial que impedía a los ricos colonos comerciar por sus propios medios con otros destinos que no fuera la metrópoli, el comercio en la zona del Caribe era importante y continuo, llegando a exportarse productos hasta el actual territorio de los Estados Unidos. ${ }^{9}$

Fue así que Saint Domingue, nombre que se le dio al territorio, se convirtió en la joya del Imperio. Según Aimé Césaire, Saint Domingue era a la economía francesa del siglo XVIII, más que toda África a la economía francesa del siglo XX. ${ }^{10}$
A principios del siglo XVIII constituía la posesión ultramarina más rica del Nuevo Mundo. Su prosperidad se basaba en dos factores: la competitividad de sus materias primas y su sistema de trabajo esclavo. Saint Domingue se especializaba en la producción de azúcar y de otros productos como el café, el índigo, el algodón y el añil. Poseía además, antes de la Revolución Francesa, 793 trapiches, 3150 añilerías, 789 algodonarías, 317 cafetales, 182 destilerías de aguardiente de caña, 50 plantaciones de cacao y caleras, tejares, etc. ${ }^{11}$

El área más rica de la colonia era la del norte, donde se encontraban las plantaciones de azúcar, café y añil más grandes y productivas. Era también, la más poblada y donde la diferenciación social estaba más marcada, con un dominio pleno de los colonos blancos sobre los demás sectores. Su capital Le Cap Francaise, era el puerto más grande de toda la colonia y contaba con todos los lujos que se podían obtener en París. La región Central era comparativamente menos próspera, pero también existían numerosas plantaciones y esclavos. Su capital era Puerto Príncipe, importante ciudad pero sin el esplendor de la anterior. La zona Sur, al estar surcada por cadenas montañosas, se encontraba un poco aislada, por lo que contaba con menos habitantes que las anteriores, y no era tan rica como ellas. Otro factor que la distinguía, además de su aislamiento, era el demográfico. La población estaba compuesta por un alto porcentaje de mulatos y negros libres en relación con los blancos. Esta diferencia era aún mayor que en las otras dos áreas.

Para poner en actividad el sistema productivo era necesaria una cantidad im- 
portante de mano de obra, el segundo factor relevante en el desarrollo de la colonia. Los nativos habían sido casi exterminados por los españoles, por lo que los colonos blancos franceses -y también españoles, como ya señalamos anteriormente- utilizaron negros esclavizados. La base y el centro del sistema colonial era la esclavitud, puesto que como sistema de explotación y, simultáneamente, de dominación, moldeaba y contenía a toda la sociedad. Una sociedad que era jerárquica y desigual, tanto en lo económico como en lo político y en lo racial. Estos dos ejes marcaban las distintas clases o castas, estando determinadas básicamente por el factor racial más que por el económico.

En la cima de este esquema se encontraban los blancos franceses, tanto europeos como criollos. Eran, en el momento previo a la Revolución Francesa, aproximadamente unas treinta mil personas. ${ }^{12}$ Este grupo no era homogéneo puesto que se reconocían fracturas internas debido a la desigual acumulación de capital político, económico y social respectivamente. Estaban divididos en tres sectores. En un primer grupo, estaban los funcionarios y políticos coloniales, quienes se dedicaban a la administración y estaban en estrecha relación con el poder metropolitano. Casi todos los que integraban este segmento provenían de Francia. Le seguían los llamados Grandes Blancos -alrededor de veinte mil franceses- comerciantes y terratenientes que eran los dueños de las grandes plantaciones y de una gran cantidad de esclavos. Eran poderosos económicamente pero sin poder alcanzar puestos políticos y estaban limitados comercialmente por el monopolio metropolitano. Por últi- mo, estaban los Pequeños Blancos -unos diez mil franceses-, en su mayoría eran pobres cuyo único capital era el color de su piel. ${ }^{13}$ Este grupo estaba compuesto por artesanos, marineros, empleados, etc.

Otro grupo, claramente diferenciado por su color de piel, lo constituían los denominados Affranchis, mulatos y negros libres, que poseían cierto capital económico y además tenían tierras, haciendas y, por consiguiente, esclavos. Se estima que este grupo lo constituían unas treinta mil personas. ${ }^{14}$ Auque eran más acaudalados que los Pequeños Blancos, eran sometidos a un estricto control social-racial, impidiéndoseles realizar determinadas actividades -no podían ejercer cargos públicos, no podían obtener la ciudadanía, o altos cargos en el ejército- o se les asignaban sectores separados en lugares públicos, como por ejemplo en los teatros, o se les impedía ejercer profesiones liberales, entre otras restricciones. Otra forma de segregarlos era la obligación que tenían de cumplir servicio en una fuerza militar de seguridad dedicada a controlar las plantaciones y a perseguir a los esclavos cimarrones. ${ }^{15}$ Podían enviar a sus hijos a estudiar a Francia -donde entraron en contacto con las ideas y los movimientos que allí se estaban gestando- hasta que esto fue prohibido en 1777; un año mas tarde, se les prohibió contraer matrimonio con colonos blancos. Como ya señalamos, este grupo era más numeroso en el sur que en las otras regiones, por lo que tenían mas poder que los Pequeños Blancos.

El escalón más bajo de esta sociedad lo constituían los esclavos negros. Se estima que eran unos 480 mil en 1789. Antes de esta fecha la mayoría de estos eran bozales, ${ }^{16}$ 
pero a partir de allí fueron mayoritariamente criollos. Los esclavizados se desempeñaban en todo tipo de actividades, tanto rurales como domésticas, siendo las principales las tareas relacionadas con las plantaciones. Aunque eran mayoría, numéricamente hablando, no tenían derechos políticos y estaban sometidos a todo tipo de arbitrariedad y castigo.

Esta estratificación social funcionó por un tiempo, pero al expandirse la economía colonial, o sea al desarrollarse cada vez más la producción de las plantaciones e ir aumentando la riqueza de las clases dominantes, las contradicciones se hicieron cada vez mas notorias. Contradicciones que surgieron no solamente entre los distintos grupos sociales, sino que también se intensificaron las existentes hacia el interior de cada uno de ellos.

Estas contradicciones se manifestaron de diferentes maneras, según cual sea el sector o la clase social que demandaba una satisfacción a sus reclamos. Estos cuestionamientos -que iban desde simples quejas, hasta peticiones formales al rey para satisfacer alguna demanda, o hasta resistencias violentas con insurrecciones-, se sucedieron en el tiempo. Pero hubo un levantamiento de esclavos que finalmente triunfó, y aunque tenía en apariencia las mismas características que los anteriores, sin embargo logró diferenciarse. Nos preguntamos entonces, ¿cuáles fueron los motivos que llevaron a que la revuelta de esclavos de 1791 triunfara?

\section{Tensiones y conflictos: la rebelión de esclavos}

Cada una de las clases sociales en la colonia de Saint Domingue tenía diferentes pretensiones, ciertos y determinados objetivos que muchas veces terminaban en verdaderas refriegas de índole político $\mathrm{y}$, casi siempre, económico. Los Grandes Blancos, quienes detentaban el poder económico, querían acceso a las decisiones políticas y administrativas de la colonia y a poder comerciar libremente sin el control metropolitano. Por ello se enfrentaban con la metrópoli y con los industriales de Burdeos, Marsella o Nantes. Los Pequeños Blancos se enfrentaban con los Grandes Blancos, porque querían participación política y, sobre todo, económica, por ser franceses "debían" tener acceso a los privilegios que daba vivir en una colonia, o sea tener tierra y esclavos. Por su parte, los Affranchis reclamaban igualdad con los Grandes Blancos, ya que lo único que los separaba era el color de su piel. Los mulatos y negros libres tenían una buena posición económica y social y pretendían formar parte de la "sacarocracia". Y por último, estaban los reclamos de los esclavos que pretendían su libertad, aspiraban a terminar con la superexplotación por lo que estaban enfrentados a los otros grupos y también entre ellos mismos por los medios a utilizar para lograr sus objetivos.

Estos intereses se contraponían y llevaban a todo tipo de enfrentamientos, por lo que la única forma de controlarlos era la violencia, en particular hacia los sectores más bajos de la sociedad. 
Los esclavos resistieron de diversas maneras la violenta dominación física, económica, cultural y religiosa que se les imponía. La resistencia implicaba acciones de tipo individual o colectiva. Las primeras, consistían en actos cotidianos, que iban desde el hurto de pequeños objetos al robo de bienes o productos, pasando por la holgazanería, o por realizar con suma lentitud las labores, hasta el maltrato hacia el amo o incluso llegar a causarle la muerte. Las acciones colectivas implicaban la huida masiva hacia áreas alejadas del control europeo -en la montaña o zonas selváticas- donde se recreaban sociedades autónomas, intentando reeditar relaciones de las "antiguas" sociedades africanas, como por ejemplo la familia ampliada, la tenencia comunitaria de la tierra, etc. Estas sociedades cimarronas crecieron con rapidez, y con la misma rapidez fueron combatidas y perseguidos sus miembros, puesto que significaban un peligro para las clases dominantes. Allí, en esas comunidades rebeldes, se crearon lazos entre los que habían sido arrancados de sus tierras, de su cultura, los que habían perdido a sus familias, sus bienes, los que solamente tenían como único valor sus vidas.

Había otras formas de resistencia que, además, ponían en cuestionamiento la visión del mundo que intentaba trasmitir el dominador, la contracultura de los esclavos, conformada principalmente por el vudú y el creole. De origen sincrético, ambas expresiones les brindaban cierta fuente de identidad a los esclavos (que provenían de diferentes etnias africanas) y les permitía vehiculizar sus anhelos de libertad. ${ }^{17}$
Estos tres elementos, la religión, el lenguaje y la forma de vida "rebelde", producían esporádicamente estallidos violentos que se manifestaban en revueltas contra las clases dominantes. Podríamos denominar a estas rebeliones como de tipo "tradicional", ya que los esclavos que se levantaban contra los amos, asesinándolos, o, como fue el caso de la rebelión de Makandal en 1750, envenenándolos masivamente, ${ }^{18}$ solo pretendían "restaurar el orden", un orden que les permitiese replegarse sobre sus tradiciones religiosas y sobre sus identidades culturales africanas, remarcando el mito sobre el retorno a África. ${ }^{19}$

Estos "modos tradicionales" de actuar estuvieron presentes en la revuelta de esclavos que estalló en 1791, pero la situación general, tanto interna de la isla como fuera de ella, no era la misma. Se produjeron una serie de cambios que podríamos clasificar de estructurales y otros coyunturales que hicieron de este levantamiento de esclavos la simiente de la lucha por la independencia. Pero destaquemos que los hechos estructurales, los internos a la relación intra-colonial, fueron los que primaron, los coyunturales solo aceleraron o modificaron algunas situaciones.

El desarrollo "industrial" de los productos de plantación, en especial el del azúcar, sufrieron un gran impacto por estos cambios. Por ejemplo, la independencia de los Estados Unidos en 1776 no solo produjo cambios a nivel económico en la región del Caribe -por la necesidad de nuevos mercados- sino que se proyectó como un modelo político posible a seguir para los colonos blancos que buscaban romper los lazos colo- 
niales. En 1784 la Corona francesa, intentando acallar las continuas quejas y reclamos de la "sacarocracia", habilitó ocho puertos para comerciar con los Estados Unidos. Esto favoreció la "industria" de plantación, pero marcó el inicio del fin. Este huevo de la serpiente logró agitar aún mas la situación interna de la isla. El gran desarrollo productivo de Sanit Domingue era el resultado de una empresa verdaderamente capitalista, como señala Gruner, una empresa "moderna", ${ }^{20}$ pero cuya base era la explotación a gran escala de mano de obra muy barata, la esclavizada. Como señala este autor, aquí tenemos una de las grandes contradicciones del modelo colonial de plantación: el desarrollo de la industria "moderna" conjugada con modos "tradicionales" de explotación. ${ }^{21}$ La relación "dialéctica" entre estos dos elementos, como señala Gruner, sentó la base de las tensiones y conflictos que fueron una de las constantes en la isla. Esta situación no solo se dio en el mundo productivo, entre formas no libres de trabajo chocando con formas industriales desarrolladas, sino que implicó también la constante tensión entre la "cultura de los esclavos", su visión del mundo, en oposición a la de los esclavócratas, los dominadores, los que detentaban lo "moderno".

Retomando el hilo, otro efecto de la independencia de Estados Unidos, fue el político. Era una clara muestra para la "sacarocracia" de que se podían independizar de la metrópoli, que podían luchar por el autogobierno. Pero no coincidían en que forma de gobierno elegir, y si convenía mantener algún tipo de vínculo con Paris o no.
Al momento de estallar la Revolución Francesa en Saint Domingue los esclavócratas estaban en conflicto, ya sea con la autoridad metropolitana o internamente. Los Grandes Blancos aprovecharon esta coyuntura para hacer oír sus quejas en los Estados Generales a donde enviaron representantes -los representantes de los Affranchis no fueron aceptados-, pero eran cautos puesto que desconfiaban de los aires igualitarios que iban prevaleciendo en los revolucionarios franceses.

La revolución en la metrópoli llevó a los sectores dominantes a replantearse sus deseos de autonomía. ${ }^{22}$ Las tensiones entre los Grandes Blancos, los Pequeños Blancos y los Affranchis fueron creciendo a medida que las decisiones tomadas por los Estados Generales primero y por la Asamblea Nacional luego, afectaban los intereses de alguno de ellos. Por ejemplo en marzo de 1790 la Asamblea Nacional decretó la formación de Asambleas coloniales en las cuales estuviesen representados los ciudadanos propietarios, sin aclarar la cuestión racial. Por supuesto que los blancos se negaron a aceptar la participación de los mulatos y negros libres. Esta experiencia legislativa generó un gran conflicto político entre los Pequeños Blancos revolucionarios plebeyos y autonomistas, los Grandes Blancos contrarrevolucionarios -a esta altura no tenían dudas de las intensiones igualitarias de los revolucionarios- y los Affranchis que fueron excluidos de la Asamblea Colonial. La disputa adquirió tanta violencia que el Gobernador, al mando de las tropas realistas, disolvió la Asamblea y anuló todos sus decretos. Pero las agresiones no terminaron, los Affranchis 
se levantaron en armas para hacer cumplir el decreto. Esta insurrección estaba liderada por Vincent Ogé y Chavannes. Los mulatos y negros libres fueron duramente reprimidos y sus jefes descuartizados. Cuando esta noticia llegó a París, causó estupor. Fue así que en 1791, en un renovado giro político, la Asamblea dictó un nuevo decretó que ahora sí establecía explícitamente la ciudadanía activa para todos los hombres libres de color y los blancos. ${ }^{23}$ Los Affranchis "ganaron", por el momento, esta pulseada.

Este fue el telón de fondo al momento del levantamiento de esclavos de agosto de 1791. Éste tenía todas las características de las rebeliones "tradicionales". Su líder, Boukman, celebró en creole, en la noche del 21 de agosto, una ceremonia vudú en un bosque cercano a una plantación en la zona norte de la isla. A partir de ese momento los esclavos arrasaron con todo lo que se pusiera a su frente, masacrando a sus amos, quemando y destruyendo. Pronto la rebelión fue tomando forma de guerrilla bajo el mando de líderes como Jean Françoise, Georges Biassau, Jeannot y Toussaint Louverture -quien en unos años se transformaría en el líder indiscutido-.

\section{De la esclavitud a la independencia}

Para 1791 la situación en la isla era crítica: los blancos enfrentados con los mulatos y negros libres en el centro y sur; y los esclavos armados, que ya formaban un ejército en las zonas selváticas, en especial en el Norte. Fue así que la Asamblea Legislativa envió, a finales de ese año, a cinco comisionados. Estos últimos intentaron lograr un acuerdo entre los blancos y los esclavos, pero fracasaron. ${ }^{24} \mathrm{Al}$ año siguiente, los jefes de los esclavos insurrectos tomaron la iniciativa para poder lograr la paz, pedían la abolición de la esclavitud y regresar a sus tareas en las plantaciones a cambio de un salario. ${ }^{25}$ También fracasaron las negociaciones y la situación se mantuvo igual. Sin embargo hay una diferencia de criterio entre los líderes negros, Toussaint no aceptó esas negociaciones y se mantuvo al margen de ellas.

Llegó una segunda misión de Comisionados en 1792, los que tuvieron un rol fundamental en los sucesos posteriores. Entre ellos están Sonthonax y Polverel. Su misión era hacer cumplir la nueva ley -garantizando que los Affranchis participaran en la Asamblea- y terminar con las revueltas, aunque no traían órdenes de abolir la esclavitud. ${ }^{26}$

Los Comisionados disolvieron el gobierno colonial, destituyendo al gobernador y a la Asamblea colonial de los blancos, y formaron un nuevo poder con una amplia participación de los Affranchis. Estas nuevas medidas no hicieron más que recrudecer los odios e incrementar la violencia. Pronto los esclavócratas -tanto blancos como mulatos- del centro y sur de la isla comenzaron a armar a sus esclavos para poder enfrentarse entre sí o para resistir a los comisionados. Esto les permitió a los esclavos hacerse de armas y así levantarse contra sus amos, como los rebeldes del norte. ${ }^{27}$

A la complicada situación de la isla se le sumó otro hecho coyuntural, la presencia de ingleses y españoles que habían entrado en guerra con la metrópoli en defensa del sostenimiento de la monarquía gala. Esto 
llevó a la transformación de una rebelión social en una guerra internacional. Cada uno de los sectores sociales actuó según su conveniencia, intentado alcanzar sus objetivos. España intervino del lado de los esclavos rebeldes del norte. La Corona ibérica les prometió la libertad a cambio de pelear a su favor en contra del gobierno de la República francesa. Toussaint aceptó esta invitación.

Por su parte el comisionado Sonthomax, ante la imposibilidad de dominar a los Grandes Blancos -monárquicos y aliados con el nuevo gobernador-, se vio en la necesidad de prometer lo mismo a los esclavos a cambio de que le prestaran su apoyo militar. La táctica resultó exitosa, y Sonthonax logró derrotar a los blancos contrarrevolucionarios en el norte de la colonia. Los esclavocratas blancos huyeron de la isla dejando sus bienes y propiedades.

De esta forma el 11 de junio de 1793 se otorgó la libertad a los esclavos que habían luchado del lado de la República. Un mes más tarde se amplió este derecho a las familias de los que luchaban en el ejército, buscando así ampliar las tropas. El 20 de agosto fue abolida la esclavitud en la zona norte de la isla. Pero estas medidas fueron tomadas por el comisionado, no por el gobierno francés.

La misma táctica se utilizó en el centro y en el sur, pero para frenar el avance de los Grandes Blancos aliados a los ingleses. El comisionado Polverel también declaró la abolición de la esclavitud.

Pese a todo esto, Toussaint se mantuvo junto con su ejército del lado de España. Desconfiaba de lo que pudiese suceder con las decisiones de los comisionados, y que la metrópoli no ratificara sus acciones. Pero debido a que en Francia el poder había sido tomado por los jacobinos, a finales de 1793 y principios de 1794, la situación se modificó. La Asamblea se radicalizó, giro hacia la izquierda, y el 4 de febrero de 1794 se decretó la libertad de los esclavos en todas las colonias. $^{28}$

A partir de aquí los hechos se desencadenaron rápidamente. Toussaint se pasó del lado de la República y combatió exitosamente a ingleses y españoles hasta expulsarlos de la isla. A partir de aquí se convirtió en jefe indiscutido de los ex-esclavos. Por su parte en el resto de Saint Domingue, los mulatos acumularon poder al vencer la alianza entre los ingleses y los Grandes Blancos.

Para cuando cambiaron los rumbos en la metrópoli nuevamente, la relación de fuerzas en la colonia se había inclinado del lado de los ex-esclavos y de los mulatos.

En 1795, el Directorio firmó con España un tratado por el cual esta última se retiró de la contienda y la isla quedó totalmente en manos francesas. ${ }^{29}$ Inmediatamente Toussaint tomó posesión del lado este de la isla -pero no ocupó Santo Domingo-.

Los mulatos intentaron destituir al Comisionado francés, quien fue rápidamente socorrido por Toussaint, logrando así obtener el cargo de general, comandante de la región del oeste y vice gobernador de la colonia. A su poder militar se le sumó el político. ${ }^{30}$

La expulsión de los ingleses en 1798 por los ejércitos combinados de Toussaint y Rigaud -el líder mulato- no trajo la paz. Al poco tiempo de esta victoria internacional, la guerra volvió a estallar pero esta vez 
como conflicto entre la región del Norte, hegemonizada por la nueva elite negra liderada por Toussaint, y la de los mulatos en el sur, comanda por Rigaud. La guerra de los Cuchillos, como se conoce a este enfrentamiento cuya crueldad es la muestra de las contradicciones de la sociedad haitiana. ${ }^{31}$ Una vez contenidos los Grandes Blancos en sus revueltas, las diferencias entre los Affranchis y los negros ex-esclavos se hizo evidente. Los mulatos pretendían restablecer su poder económico, peor ahora acompañado por cierto poder político; mientras que los negros no iban a permitir ningún tipo de forma de trabajo forzado. Los mulatos del sur fueron aplastados después de casi un año de enfrentamientos por uno de los lugartenientes de Toussaint, Jean Jacques Dessalines.

\section{Amodo de cierre}

A pesar del estado de conflicto y caos en que estuvo sumida Saint Domingue desde 1791, Toussaint planteó un proyecto de reorganización económico claro y preciso que llevó a la recuperación económica en pocos años. ${ }^{32}$ Este proyecto fue desarrollado primero en el Norte y Centro de la isla, cuando en 1797 quedó como líder indiscutido; en el Sur lo hizo recién en 1800, cuando fueron derrotados los mulatos.

Su principal preocupación fue impedir el restablecimiento de la esclavitud y reorganizar la economía de la isla. Como primera medida impuso un control laboral estricto: los ex-esclavos debían trabajar en las plantaciones a cambio de un salario que representaba un cuarto de lo que se producía en ella. Con esto se limitaba el poder de los dueños, se controlaba el trabajo, y se impedía la fragmentación de la tierra en pequeñas propiedades. Toussaint pretendía restablecer la riqueza y el esplendor económico, por ello debía reorganizar el sistema moderno de producción, o sea el de plantación. Para lograrlo estableció un fuerte control estatal sobre la economía y las plantaciones. En el primer aspecto impuso el cobro de impuestos a los dueños de los ingenios y controló militarmente el régimen laboral. El Estado contaba con plantaciones propias, y fomentó el retorno de los antiguos dueños para que explotaran sus antiguas posesiones, pero ahora no serían más los amos sino que serían propietarios. Los que regresaron formaron junto a los ex-esclavos que habían ascendido socialmente por la vía de las armas, una nueva elite. Ahora el componente racial se había "borrado", y las diferencias se basaban en lo económico y en el prestigio.

Otro de las iniciativas tomadas por Toussaint fue la redacción de una constitución en 1801. Este hecho es de suma importancia ya que marca los deseos de igualdad y universalidad de esta nueva elite de Saint Domingue, pero marca también su contradicción, ya que no rompe con la metrópoli, no declara la independencia.

Los éxitos económicos, pero sobretodo la redacción de la Constitución, hicieron que Napoleón enviara tropas para terminar con el poder de Toussaint, restablecer el poder de los colonos y reimplantar la esclavitud.

La tropas francesas se encontraron con la resistencia de de los ex-esclavos de Toussaint. El ejército de éstos iba ganando en la lucha, hasta que a causa de una traición, Toussaint fue capturado y enviado a Fran- 
cia, donde murió en una fría y sucia celda. Sin embargo las tropas metropolitanas fueron vencidas al poco tiempo debido a la conjunción de la feroz lucha de las de las fuerzas haitianas, ahora dirigidas por Dessalines, que utilizaron la técnica de guerrilla y la fiebre amarilla, que diezmo al ejército francés.

Las tropas de ex-esclavos no solo luchaban ahora por conservar su libertad sino que se agregó un nuevo componente, la independencia. Bajo estas dos banderas, las fuerzas rebeldes de negros se unieron con los mulatos y lograron vencer a las entrenadas tropas francesas a finales de noviembre de 1803.

Desallines tomó el poder y declaró el 1 de enero de 1804 la independencia de Haití y dictó una nueva Constitución. En ella se proclamó, inspirándose en los ideales de Tousaint Louverture, que todos los ciudadanos haitianos, sea cual sea su color de piel, serían a partir de ese momento llamados negros. ${ }^{33}$ Con ello los "jacobinos negros" llevaron adelante sus principios, sin limitaciones. Nació así el primer Estado libre, con igualdad para todos sus ciudadanos en América.

\section{Resumo}

Neste trabalho procuramos analisar as transformações produzidas no processo revolucionário haitiano, tratando de compreender sua originalidade e complexidade. Suas particularidades - do que começou como uma rebelião econômico-social e que culminou com a luta pela independência -, tensões e contradições, objetivadas em variáveis estruturais própria da lógica colonial em Saint Domingue/Haiti, se conjugam com certos aspectos conjunturais, definindo o nascimento e identidade da primeira República de ex-escravos negros no mundo.

Palavras-chave: Haiti. Rebelião de escravos. Revolução haitiana.

\section{Abstract}

This paper attempts to analyze the changes that occurred in the Haitian revolutionary process, trying to understand its uniqueness and complexity. Its peculiarities -emerged as a socioeconomic rebellion and culminated in the struggle for independence- its tensions and contradictions, objectified in structural variables characteristic of colonial logic in Saint Domingue / Haiti, are combined with situational aspects, thus defining the birth and identity of the first republic of former slaves in the world.

Keywords: Haiti. Haitian Revolution. Slave rebellion.

\section{Notas}

1 Gruner, Eduardo (2010). La oscuridad y las luces. Capitalismo, cultura y revolución, Edhasa, Buenos Aires.

2 Feijo, María Cecilia y Scolnik, Fernando (2011). "Revolución burguesa, revolución anti-esclavista y de independencia en la América colonial: el caso de la revolución de Saint Domingue / Haití", en Cuadernos de Marte, año 2, n², p. 77-102.

3 James, Cyril Lionel (2003). Los jacobinos negros. Toussaint L'Ouverture y la revolución de Haití, FCE, España.

4 Mezilas, Glodel (2010). La Revolución haitiana de 1804 y su impacto sobre América Latina, en Escenarios XXI, Año 1, n 3, septiembre, p. 19-38. 
5 Fernández Retamar, Roberto (2006). Pensamiento de nuestra América. Autorreflexiones y propuestas, CLACSO, Buenos Aires, p. 15.

6 Haití ocupa un tercio de la isla La Española, denominada así por Cristóbal Colon en 1492. El resto del territorio esta ocupado por la República Dominicana.

7 Tratado de Ryswick, 1697.

8 En 1503 se realizó el primer pedido de mano de obra, y en 1510 se autorizó el primer envío de esclavos a La Española, en Hugh, Thomas (1997). La trata de esclavos, Planeta., Buenos Aires.

9 Martínez Peria, Juan Francisco (2009a). Haití: la revolución olvidada, en e-l@tina, Revista electrónica de estudios latinoamericanos, volumen 7 , número 27, abril-junio, http://www.iealc.fsoc. uba.ar/ elatina.htm, p. 6.

10 Cfr. Cesarie, Ainé (1962). Toussaint Louverture. La revolución francesa y el problema colonial, Presence Africaine Paris.

11 Martínez Peria, Juan Francisco (2009a). op. cit., p. 5.

12 Ibídem, p. 6 y Vitale, Luís (1987). Haití: primera nación independiente de América Latina, en Revista Todo es Historia, $n^{\circ} 245$, noviembre.

13 Habían sido llevados a la isla como colonos, pero no fueron eficientes en su trabajo por lo que fueron sustituidos por esclavos negros, Vitale, Luís (1987). Ibídem.

14 Martínez Peria, Juan Francisco (2009a). op. cit., p. 6 y Vitale, Luís (1987). op. cit.

15 Martnez Pería, Juan francisco (2009a). op. cit., p. 7.

16 Martinez Peria, Juan Francisco (2009b). “Makandal, el profeta de la libertad (parte I)", en los nuestramericanos, su historia, http:/ / www.centrocultural.coop/blogs/nuestramericanos/2009/09/20/ ma kandal-el-profeta-de-la-libertad-parte-i/

19 Guner, Eduardo (2010). op. cit., p. 339-418.

20 Ibídem.

${ }^{21}$ Cfr. Genovese, Eugenio (1971). Esclavitud y capitalismo, Ed. Ariel, Barcelona.

22 Vitale, Luís (1987). op. cit.

23 Martínez Peria, Juan Francisco (2009a). op. cit. p. 10.

24 Feijo, Maria Cecilia y Scolnik, Fernando (2011). op. cit., p. 80-90.

25 Maertínez Peria, Juan Francisco (2009a). op. cit., p. 12.

26 Feijo, Maria Cecilia y Scolnik, Fernando (2011). op. cit., p. 90 .
27 Martínez Peria, Juan Francisco (2009a). op. cit., p. 12.

28 Feijo, Maria Cecilia y Scolnik, Fernando (2011). op. cit., p. 90.

29 Martínez Peria, Juan Francisco (2009a). op. cit., p. 14.

30 Ibídem

31 Ibíd. p. 15.

32 Ibídem, p. 16-18 y Gruner, Eduardo (2010). op. cit., p. 267-338.

33 Gruner, Eduardo (2010). op. cit., p. 88. 